\title{
Are publicly available internet resources enabling women to make informed fertility preservation decisions before starting cancer treatment: an environmental scan?
}

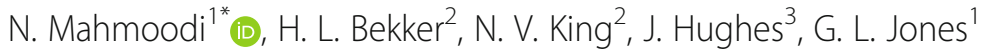

and on behalf of the Cancer, Fertility and Me research team

\begin{abstract}
Background: To identify publicly available internet resources and assess their likelihood to support women making informed decisions about, and between, fertility preservation procedures before starting their cancer treatment.

Methods: A survey of publically available internet resources utilising an environmental scan method. Inclusion criteria were applied to hits from searches of three data sources (November 2015; repeated June 2017): Google (Chrome) for patient resources; repositories for clinical guidelines and projects; distribution email lists to contact patient decision aid experts. The Data Extraction Sheet applied to eligible resources elicited: resource characteristics; informed and shared decision making components; engagement health services.

Results: Four thousand eight hundred fifty one records were identified; 24 patient resources and 0 clinical guidelines met scan inclusion criteria. Most resources aimed to inform women with cancer about fertility preservation procedures and infertility treatment options, but not decision making between options. There was a lack of consistency about how health conditions, decision problems and treatment options were described, and resources were difficult to understand.

Conclusions: Unless developed as part of a patient decision aid project, resources did not include components to support proactively women's fertility preservation decisions. Current guidelines help people deliver information relevant to treatment options within a single disease pathway; we identified five additional components for patient decision aid checklists to support more effectively people's treatment decision making across health pathways, linking current with future health problems.
\end{abstract}

Keywords: Patient decision aid, Shared decision making, Fertility preservation, Cancer treatment, eHealth, Environmental scan

\footnotetext{
* Correspondence: N.Mahmoodi@leedsbeckett.ac.uk

1 Department of Psychology, School of Social Sciences, Leeds Beckett

University, Leeds LS1 3HE, UK

Full list of author information is available at the end of the article
}

(c) The Author(s). 2018 Open Access This article is distributed under the terms of the Creative Commons Attribution 4.0 International License (http://creativecommons.org/licenses/by/4.0/), which permits unrestricted use, distribution, and reproduction in any medium, provided you give appropriate credit to the original author(s) and the source, provide a link to the Creative Commons license, and indicate if changes were made. The Creative Commons Public Domain Dedication waiver (http://creativecommons.org/publicdomain/zero/1.0/) applies to the data made available in this article, unless otherwise stated. 


\section{Background}

Providing accurate patient information is fundamental to health services worldwide [1]. Since the 1940s, social science research has informed guidance to enhance text readability $[2,3]$ and health communications $[4,5]$. National and academic organisations provide best practice guidance [6] for patient-focused intervention development and evaluation $[7,8]$. Research indicates patient resources informed by these standards enhance health literacy and patient benefits [9]. A challenge for service delivery is to support patient-focused communications about complex health problems; most guidance support one-off decisions about a health problem in a single pathway of care [10].

An iatrogenic consequence of cancer treatment is an increased chance of impaired fertility; treatments can permanently damage the endocrine function and/or reproductive systems needed to fall pregnant or carry a baby to term [11]. Oncologists deliver care to minimise these fertility-related effects using minimally gonadotoxic therapies [12] and/or fertility sparing procedures (e.g. trachelectomy, ovarian transpositioning, shielding) [13, 14]. For some women with impaired fertility after cancer treatment, infertility treatments are offered [15]. Having fertility preservation procedures before cancer treatment may increase the likelihood of women having genetically related children in the future, but can delay the start of cancer treatment by a few weeks. Fertility services offer the following preservation procedures: embryo cryopreservation, oocyte cryopreservation, and ovarian tissue cryopreservation $[16,17]$.

Integrating relevant fertility preservation information into cancer pathways is essential for women to make informed decisions about whether to undergo fertility preservation, and/or which procedures to choose [15, 18-25]. Receiving accurate and timely information is associated with reported better quality of life and reduced decisional regret, post cancer treatment [22, 26-29]. However, women's recall of discussions with health professionals and support about infertility-related side-effects of cancer treatment is low [18, 30, 31]; findings indicate variation in the timing, content, utility and quantity of information about fertility preservation provided by cancer services [18, 31-33].

Increasingly the internet is accessed for health information [34-38], and people find resources from stakeholders independent of healthcare services (e.g. public, professionals, charities, advocacy groups, product advertisers, unregulated businesses) and in varied formats (e.g. audio, video, text). These resources may provide accurate information to support patient and carer health literacy, or they may be misleading and difficult to understand in the context of a person's life, experience and illness. It is unclear if and how systematically best practice guidance are used to inform publically available resources $[39,40]$. This paper investigates what publically available resources are available to women about fertility preservation choices before starting their cancer treatment, and if they are sufficient to enable informed decision making.

\section{Methods}

We carried out a survey of publically available patient information and guideline resources to support women diagnosed with cancer making fertility preservation choices before treatment. We employed an environmental scan method used in applied health research for systematic analysis of Google search engine, targeted website searches and contacting experts [41-44]. We used this approach to search for resources freely available to any woman or health professional [34-38, 44]; internet searches can be more effective at identifying reports [42] and informal material relevant to the topic than academic or organisational databases $[45,46]$.

We followed the PRISMA reporting guidelines for best practice in reporting systematic reviews of secondary data synthesis [47]. These guidelines provide steps to encourage methodological rigour around the search, inclusion criteria, extraction and synthesis of findings. The target for this environmental scan is a resource (leaflet or guideline) rather than an empirical study; the quality of the target is judged against criteria known to boost reasoning rather than those known to enhance methodological rigour. A data extraction sheet was developed to elicit systematically the key characteristics and content from each resource, which are described in tables and synthesised within the results section.

\section{Study context}

This survey was carried out during the development phase of the Cancer, Fertility and Me Patient Decision Aid (CFM-PtDA) [48-50]. Other activities included (Nov 2015-Sept 2016): research governance and ethics; scoping local and national patient information provided during usual care by services to patients with cancer; mapping care pathways between cancer and fertility services in Leeds and Sheffield, UK; alpha testing [51] the CFM-PtDA prototype with patients, oncology healthcare professionals and other key stakeholders using qualitative methods. The project received ethics approval by National Health Service (NHS) Health Research Authority (HRA), East Midlands Nottingham 1 Research Ethics Committee in 2016, Ref: 16/EM/0122; HRA Ref:194751.

\section{Information sources and search strategies}

Health information is provided and used for different purposes, such as to inform, reassure, persuade, acquire skills and enhance reasoning [52-54]. We 
searched the internet for resources with minimum standards for patient decision aids known to support understanding of the health problem $[4,55,56]$; provide awareness of the advantages and disadvantages of all relevant treatment options and their consequences [52]; and support reasoned decision making [17, 5254]. These include components known to minimise bias through providing balanced, neutral information of all options and presentation of risk as natural frequencies/ percentages [57-61]; a visual representation of the decision problem $[10,62]$; an evaluation of these details in accordance with a person's values [6366]; an explanation of people's understanding of illness and treatment $[4,55,56,67]$; and allow for an informed decision to be reached and implemented with health professionals [59, 63, 68].

Three types of data source were searched between November 11th - December 17th 2015, and repeated in June 2017. Search terms, Uniform Resource Locator (URL) identifiers, and hits were managed using Excel [42]:

1. Google (Chrome) was searched using 8 unique search themes (cancer, breast cancer, leukemia, lymphoma, gynaecological, surgery, radiotherapy, chemotherapy), developed with an information specialist (NVK). Within those themes there were 9 unique strategies which contained multiple combinations of the following terms (UK and USA spellings): cancer (all types); women (patient); treatment (procedure); fertility preservation (treatment); decision-making; information (booklet, education, decision aid) (contact authors for further information). All internet web-links, including sponsored links, on the first 5 pages of each search were screened ( $n=3600$ websites) [42].

2. Open access repositories of patient decision aids, clinical guidelines and active research were searched using five search strategies developed with an information specialist (NVK): Decision Aids Library Inventory (DALI, Ottawa Health Research Institute, Canada) (https://decisionaid.ohri.ca/ cochinvent.php); Trip clinical search engine https:// www.tripdatabase.com/); Clinical guidelines databaseNICE Evidence; (https://www.evidence.nhs.uk/); Agency for Healthcare Research and Quality National Guidelines Clearinghouse - AHRQ-NGC; (https://www.guideline.gov/); UK and USA Clinical trials databases (https://www.ukctg.nihr.ac.uk/; https://clinicaltrials.gov/).

3. Experts (health professionals, patients and researchers) in patient decision aid and shared decision-making interventions and research were contacted via the SHARED-L international email distribution list. Experts were not asked to participate in the study, but to simply email the study team with information on any patient resources and guidelines which met the study criteria. Four experts responded by 31st January 2016, and all open-access resources identified $(n=4)$ were included in the study.

\section{Data selection}

Patient resources with the following criteria were included:

- Targeted women diagnosed with cancer and offered fertility preservation options,

- Described fertility problems as a consequence of cancer treatment,

- Described fertility preservation options and consequences

- Contained an explicit statement to consider fertility preservation options before cancer treatment.

Clinical guidelines with the following criteria were included:

- Raised awareness of the link between cancer treatment and fertility problems

- Contained explicit guidance on what fertility preservation options to mention to women diagnosed with cancer

- Explained the links between the fertility and cancer management pathways

- Provided explicit guidance on how to support women's choices about fertility preservation options in the context of their cancer care.

All resources were screened (NM) for inclusion in the study; NM and HLB discussed decisions about resources, included $(n=10)$, excluded $(n=10)$ and uncertain (all). The search process and criteria were discussed independently with GLJ, JH (November 2015).

\section{Data extraction}

A data extraction sheet (Additional file 1) was developed (HLB, NM) with reference to patient decision aid research reviews and resource development $[2,7,8,10,35,52-54,69,70]$, and cancer-related fertility preservation decision aids [22, 26, 27, 29, 71, 72]. The presence or absence of minimum standards and components know to support understanding of the health condition, decision problem, treatment options and their consequences, and reasoned decision making were extracted systematically from each resource meeting the scan's inclusion criteria using the data extraction sheet. The Data Extraction Sheet was piloted 
(NM, JH, GLJ), independently reviewed by the CFM-PtDA project steering group (February 2016), and applied systematically to eligible resources (NM, $\mathrm{JH})$ extracting the following:

- Characteristics: type of 'e-resource' (internetdelivered, internet-adapted, internet-available) [35], title, publisher, year of publication and of the updated year, country, authors, funders, location (URL), length, stated purpose resource.

- Quality indicators: Flesch readability formula [3] was used to measure comprehensibility of leaflet (70-79 fairly easy; 60-69 standard; 50-59 fairly difficult; 30-50 difficult; 0-29 confusing), endorsed by third party, developed systematically, listed evidence used to inform content.

- Describes health problem: label and symptoms, cause, time-line, consequences, cure and/or control, and emotional responses to a) cancer, b) fertility / infertility, and c) cancer-related infertility.

- Describes treatments: label /procedure, eligibility, prognosis, side effects short term, side effects long term for cancer treatment (chemo/ radio/ hormone therapy, surgery), fertility preservation treatments (egg/ embryo/ ovarian freezing, ovarian suppression/ shielding), and/or infertility treatments (in vitro fertilisation, adoption/ fostering, surrogacy).
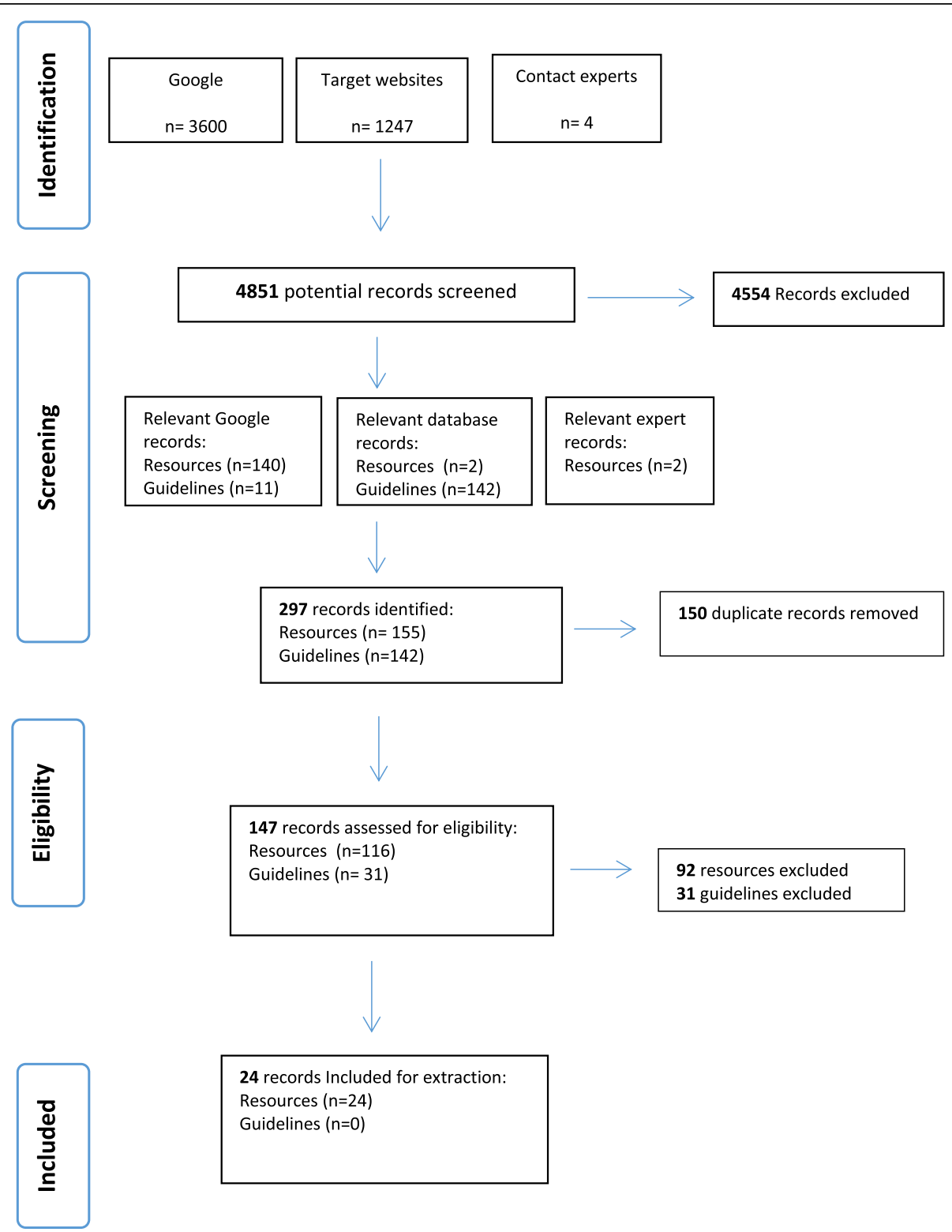

Fig. 1 Study flow diagram - Resource and guideline identification, screening, and eligibility 


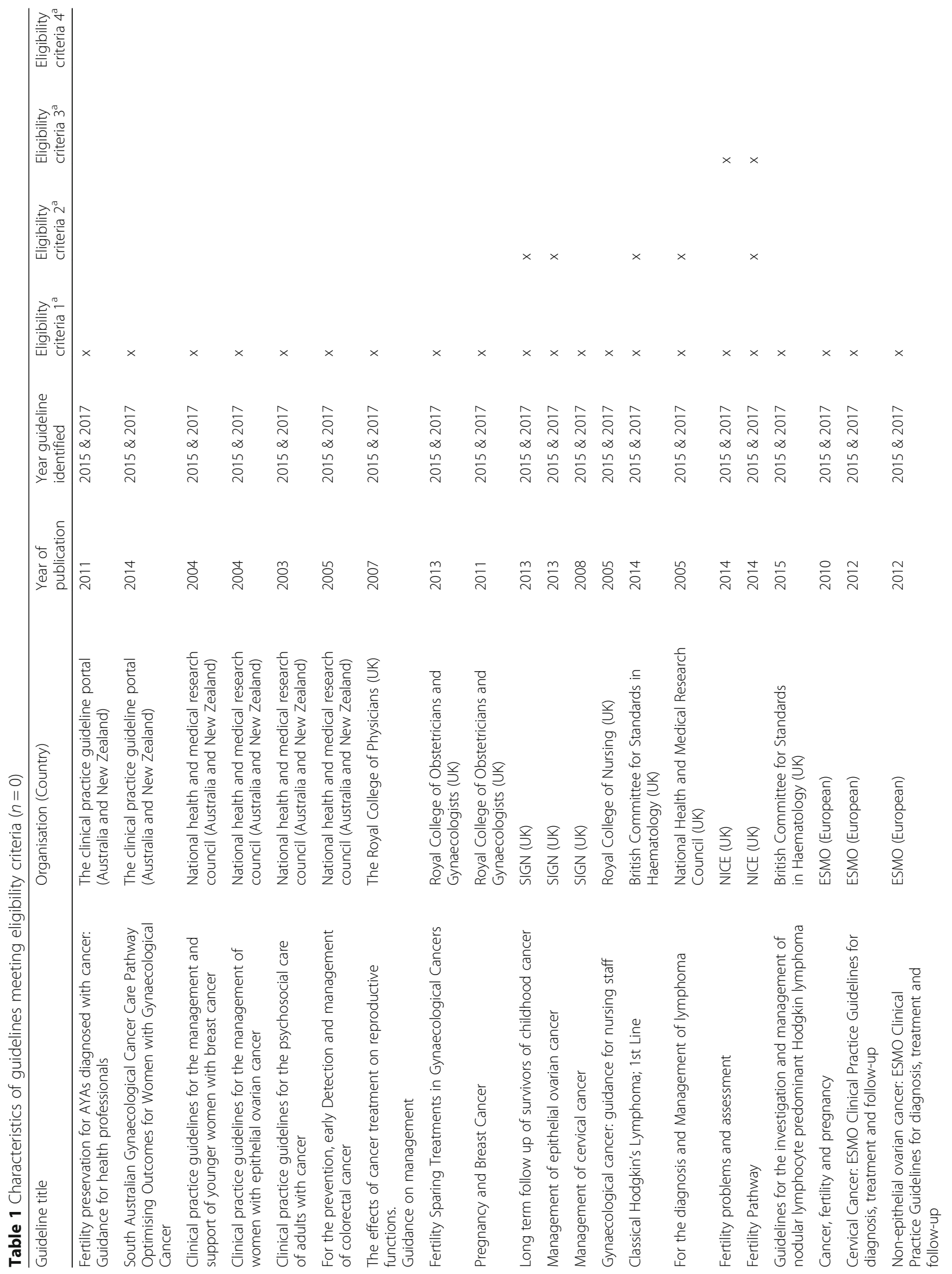




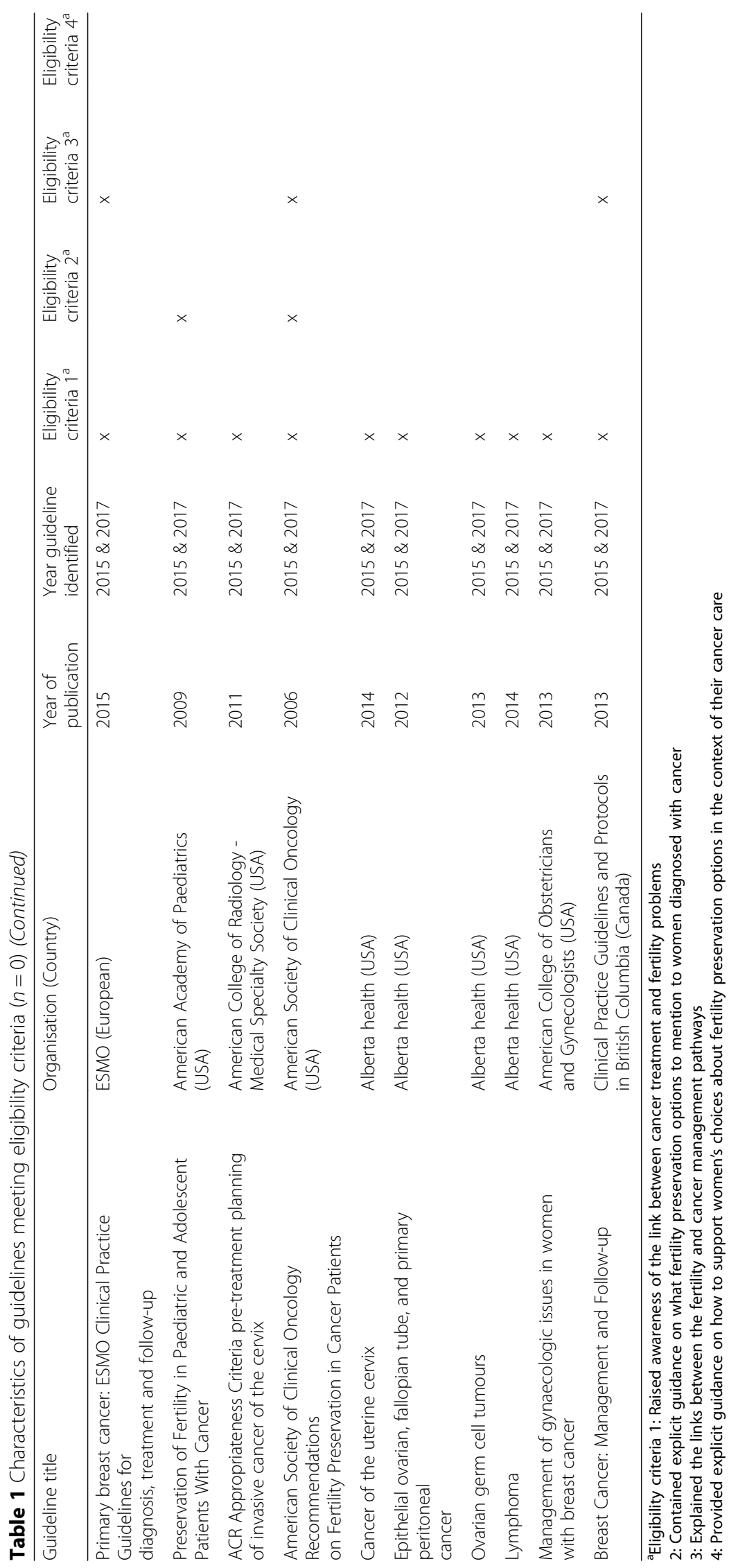




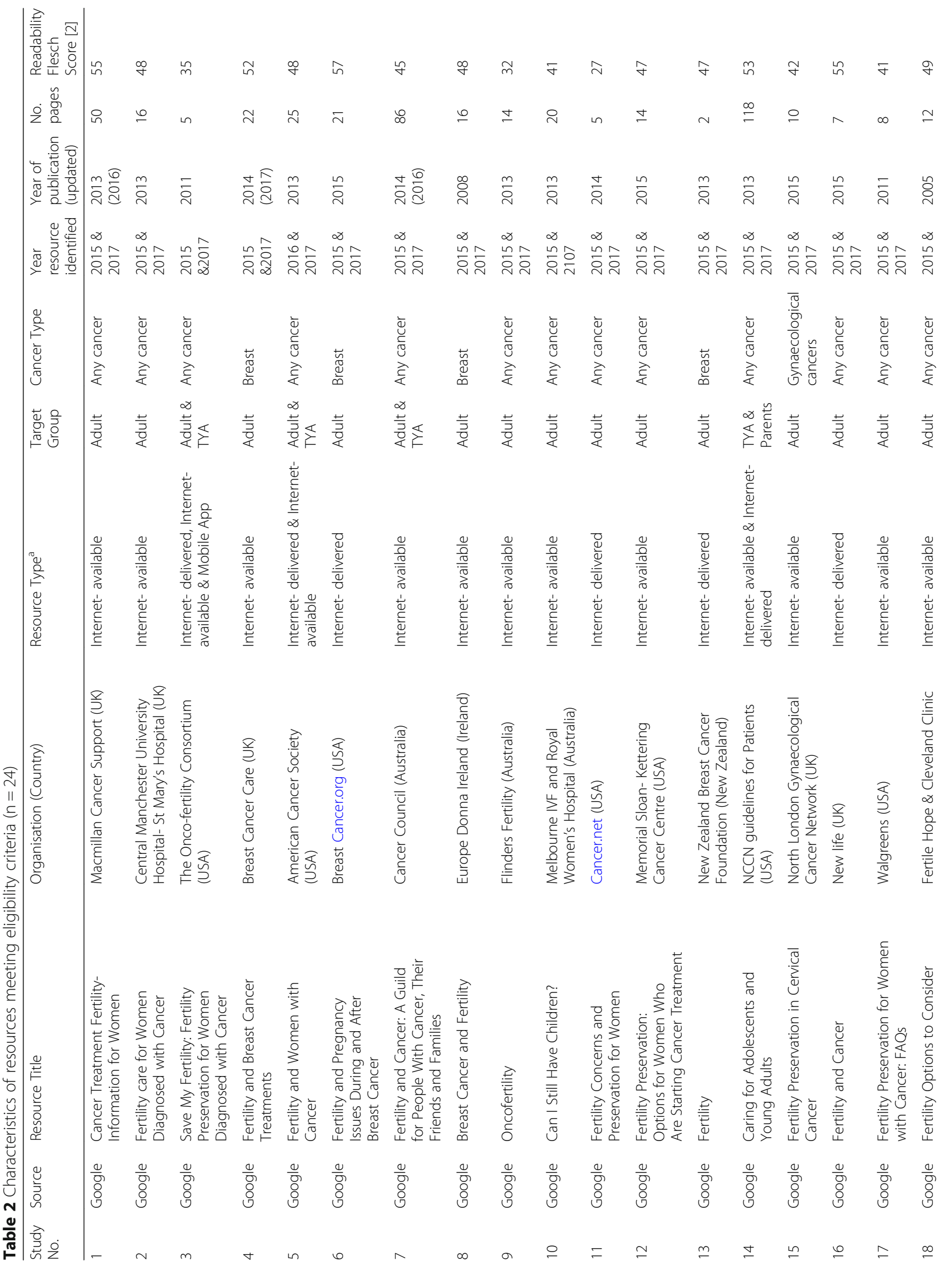




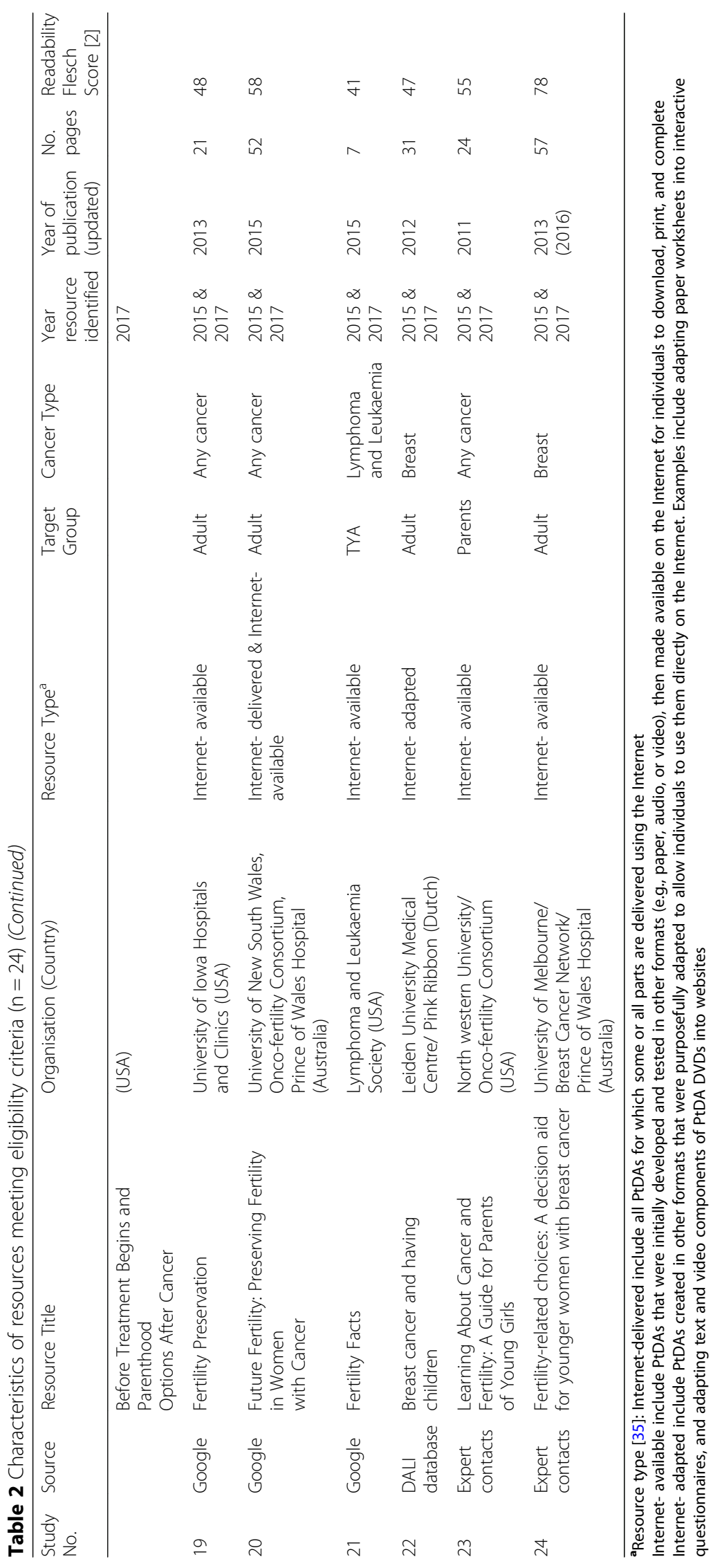


- Signposts illness-wellness trajectory: care pathways; quality of life.

- Decision architecture to boost/ bias thinking: trade-offs between options; decision picture; decision guidance; other's values/ stories; risk presentation; treatment preference.

- Health service engagement: prompts to prepare for consultations, friends and families; diagrams/ guidance to prepare for procedures; signposting to other information.

\section{Data synthesis and analysis}

Two quality-assessment grids were applied to synthesise evidence across resources: The IPDAS grid - 12 components identified as minimum criteria for a patient decision aid resources [8, 9, 44, 69, 70]; Informed DecisionMaking (IDM) grid - 10 components known to boost informed and shared decision-making, and minimise reasoning bias [52-54]. Each item scored either 0 (present) or 1 (not present); Summed total scores were IPDAS grid (0-12), and IDM grid (0-10).

The findings are presented using narratives and frequency statements to address whether or not women and health professionals have access to publicly available online resources that support fertility preservation decisions before cancer treatment. SPSS statistical software was used to manage the data elicited from the resources. Descriptive data were used to assimilate findings across resources, and show the number of occurrences for each component on the data extraction sheet.

\section{Results}

Shown in Fig. 1, the search yielded 147 unique records eligible for assessment $(n=116$ e-resources and $n=31$ guidelines). Following screening, none of the 31 guidelines met the scan's inclusion criteria (Table 1); although all guidelines make links between the consequences of cancer treatment and fertility problems, only 7 highlight guidance around availability of fertility preservation treatments, only 5 made links between cancer and fertility management pathways for women, and none provided guidance for professionals on how to support women's decision making about fertility preservation options in the context of their cancer care.

Following screening, 24 patient resources met the scan's inclusion criteria (Table 2). Most resources were suitable for women with any cancer type $(n=16)$, and most were designed for adults $(n=16)$. Resources were published between 2005 and 2017, all but one (SN22) in English, one (SN24) was judged as fairly easy to read, and one (SN22) was internet-adapted by using an interactive web-based platform (Table 2). All resources stated their publisher, thirteen described the development team, ten included references of the evidence-base informing the resource content, four stated they were endorsed by a third party, three published peer-reviewed papers demonstrating the resource's development and/or evaluation, and two were located on the publicly available DALI (Table 3).

\section{Meeting minimum standards for patient decision aid resources}

All resources eligible for the study provided information about the health conditions and treatment options (Table 4). The stated aim for 18 resources was to provide information about cancer, fertility and infertility options; 7 stated their purpose was to support making a decision between treatment options (SN8, SN10, SN11, SN12, SN18, SN22, SN24). Of these, 3 focused on decisions between having cancer treatment with or without fertility preservation (SN2, SN3, SN23), 3 between fertility preservation options (SN22, SN23, SN24), and 2 between infertility treatments to have a family (SN22, SN24).

All 24 resources encouraged women to talk to their cancer care and/or fertility specialist teams, and/or speak with friends and family; 15 (SN3, SN6, SN7, SN8, SN11, SN13, SN14, SN16, SN18, SN19, SN20, SN21, SN22, SN23, SN24) provided questions to support shared decision making in consultations with health professionals. No resources included all the components identified as part of the minimum standards for a patient decision aid [9]; the median score was 4 out of 12 points (range 2-8) (Table 4).

\section{Inclusion of components boosting or biasing informed decision-making}

There were variations in how cancer and fertility problems were described across resources (Table 5), with gaps in details to help women's understanding of the causal links between having cancer treatment and an increased likelihood of having fertility problems in the future. Most resources $(n=21)$ described fertility-related options before, during and after cancer. Four (SN14, SN22, SN23, SN24) resources used flow diagrams to illustrate links between choices and service delivery pathways. Seven provided diagrams and pictures to explain procedures (e.g. In-vitro fertilisation) (SN1, SN2, SN7, SN10, SN12, SN23, SN24) and six illustrated body systems (e.g. reproductive system) (SN1, SN7, SN10, SN11, SN12, SN23).

There was variation in the amount of information given about treatment options for the short and longterm consequences of cancer-related fertility (Table 6). Ten resources included prompts encouraging women to describe what was important to them about infertilitytreatment options (Table 7); one provided quality of life statements to help women's reasoning (SN7). Three resources used an option-by-attribute table format to summarise details (SN5, SN23, SN24), and two used 
Table 3 Assessment of Resource Development Quality $(n=24)$

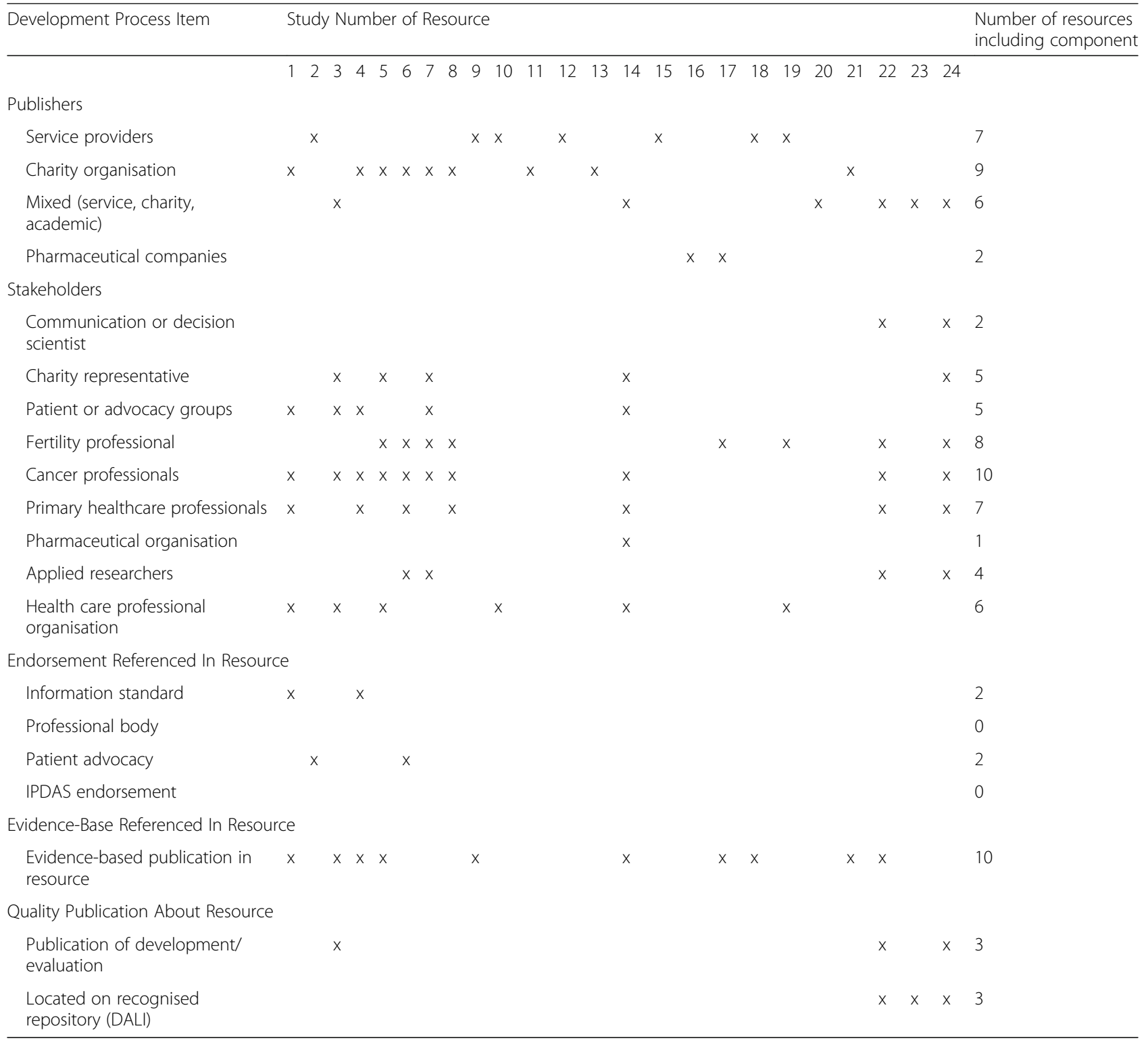

trade-offs based on their values (SN22, SN24). The health professionals' opinion was provided in two resources (SN1, SN6), and other women's stories about their experiences in four resources (SN1, SN7, SN14, SN24).

Resources provided risk statements about: cancer treatment side effects; cancer treatment impact on fertility; fertility preservation side effects to women and/or the baby; risk of cancer reoccurrence; success of fertility preservation treatments. Usually risk was presented as a verbal descriptor (e.g. low, high, likely) $(n=24)$, nine used percentages (SN2, SN6, SN8, SN15, SN16, SN18, SN19, SN22, SN24) and/or figures with the same common denominator across the resource (e.g. 1 in 100) $(n=1)(\mathrm{SN} 1)$, and three used graphs, bar charts and iconography figures (SN12, SN22, SN24). None provided information about the levels of uncertainty around event or outcome probabilities. Few provided balanced details about the risks and benefits of fertility preservation options; three (13\%) described positive features (benefits) (SN17, SN19, SN24), and eight (33\%) negative features (harms) (SN2, SN4, SN5, SN12, SN17, SN19, SN22, SN24). No resources included all the components identified for boosting informed and shared decision making [52-54]; the median score was 3 out of 10 points (range 2-8) (Table 7).

\section{Discussion}

The search strategies identified 4851 cancer and fertility resources (Fig. 1). It took six weeks of systematic analysis to identify those integrating fertility preservation options within the cancer care pathway. Those meeting the scan's 
Table 4 Resource assessed for inclusion of components within Patient Decision Aid Resources (IPDAS) $(n=24)[8,69,70]$

\begin{tabular}{|c|c|c|c|c|c|c|c|c|c|c|c|c|c|c|c|c|c|c|c|c|c|c|c|c|c|}
\hline \multirow[t]{2}{*}{ IPDAS Checklist Item } & \multicolumn{24}{|c|}{$\begin{array}{l}\text { Study Number of Resources } \\
\text { Including Component }\end{array}$} & \multirow[t]{2}{*}{$\begin{array}{l}\text { Number of resources } \\
\text { including component }\end{array}$} \\
\hline & 1 & 2 & 3 & 4 & 5 & 6 & 7 & 8 & 9 & 10 & 11 & 12 & 13 & 14 & 15 & 16 & 17 & 18 & 19 & 20 & 21 & 22 & 23 & 24 & \\
\hline $\begin{array}{l}\text { 1. Describes health condition for } \\
\text { index decision }\end{array}$ & $x$ & $x$ & $x$ & $x$ & $x$ & $x$ & $x$ & $x$ & $x$ & $x$ & $x$ & $x$ & $x$ & $x$ & $x$ & $x$ & $x$ & $x$ & $x$ & $x$ & $x$ & $x$ & $x$ & $x$ & 24 \\
\hline $\begin{array}{l}\text { 2. Explicitly describes the index } \\
\text { decision being considered }\end{array}$ & & $x$ & $x$ & & & & & & & & & & & & $x$ & & & & & & & $x$ & $x$ & $x$ & 6 \\
\hline 3. Describes the options & $x$ & $x$ & $x$ & $x$ & $x$ & $x$ & $x$ & $x$ & $x$ & $x$ & $x$ & $x$ & $x$ & $x$ & $x$ & $x$ & $x$ & $x$ & $x$ & $x$ & $x$ & $x$ & $x$ & $x$ & 24 \\
\hline $\begin{array}{l}\text { 4. Describes positive features all } \\
\text { options }\end{array}$ & & & & & & & & & & & & & & & & & $x$ & & $x$ & & & & & $x$ & 3 \\
\hline $\begin{array}{l}\text { 5. Describes negative features all } \\
\text { options }\end{array}$ & & $x$ & & $x$ & $x$ & & & & & & & $x$ & & & & & $x$ & & $x$ & & & $x$ & & $x$ & 8 \\
\hline $\begin{array}{l}\text { 6. Describes what it is like to } \\
\text { experience the psychosocial } \\
\text { consequences of options }\end{array}$ & & & & & & & & & & & & & & & & & & & & & & & & & 0 \\
\hline $\begin{array}{l}\text { 7. Shows negative and positive } \\
\text { features of all options in equal } \\
\text { detail (text amount, equal stats/ } \\
\text { consequences) }\end{array}$ & & & & & & & & & & & & & & & & & $x$ & & & & & & $x$ & & 2 \\
\hline $\begin{array}{l}8 \text { Cites evidence used or links to } \\
\text { document }\end{array}$ & $x$ & & $x$ & $x$ & $x$ & & & & $x$ & & & & & $x$ & & & $x$ & $x$ & & & $x$ & $x$ & & & 10 \\
\hline $\begin{array}{l}\text { 9. Provides a publication date } \\
\text { resource }\end{array}$ & $x$ & $x$ & & $x$ & $x$ & & $x$ & $x$ & & $x$ & & $x$ & & $x$ & & & $x$ & $x$ & & $x$ & & $x$ & & $x$ & 14 \\
\hline $\begin{array}{l}\text { 10. Provides information about an } \\
\text { update policy }\end{array}$ & & $x$ & & $x$ & $x$ & $x$ & & $x$ & & $x$ & $x$ & & & $x$ & & & & & & & & $x$ & & $x$ & 10 \\
\hline $\begin{array}{l}\text { 11. Provides information about } \\
\text { uncertainty level around event } \\
\text { /outcome probabilities }\end{array}$ & & & & & & & & & & & & & & & & & & & & & & & & & 0 \\
\hline $\begin{array}{l}\text { 12. Provides information about the } \\
\text { funding source used for } \\
\text { development }\end{array}$ & $x$ & & $x$ & & & & $x$ & & & & & & & $x$ & & & & & & & & $x$ & $x$ & $x$ & 7 \\
\hline Total score IPDAS (out of 12) & 5 & 6 & 5 & 6 & 6 & 3 & 4 & 4 & 3 & 4 & 3 & 4 & 2 & 6 & 3 & 2 & 7 & 4 & 4 & 3 & 2 & 8 & 5 & 8 & \\
\hline
\end{tabular}

criteria were predominantly information resources for women with cancer, raising awareness of fertility preservation and informing about infertility treatment options. Details describing the two related health problems, cancer and fertility problems, varied across resources. Three resources met the minimum criteria for recognition a patient decision aid [7, 9]; all three were developed and evaluated within research projects. Six used components and structures known to help people think actively about treatment options in accordance with their own values (Tables 4 and 7). No clinical guidelines enabled cancer professionals to prepare women for fertility preservation decisions and/or service referral; guidance was to read quality standards and/or clinical guidelines for treating fertility problems $[15,19]$. As health professionals are not provided with guidance on enabling fertility preservation decisions in the context of cancer rather than infertility treatment, and relevant patient information is not easily accessible, these results explain in part why women with cancer feel simultaneously unsupported and overwhelmed by information at this time-pressured point in their treatment management $[18,22,28,29,31,73]$.

Table 5 Details of health conditions described, by illness-schemata category $(n=24)$ [56]

\begin{tabular}{lllll}
\hline & $\begin{array}{l}\text { Cancer } \\
(16 / 24)\end{array}$ & $\begin{array}{l}\text { Fertility } \\
(14 / 24)\end{array}$ & $\begin{array}{l}\text { Infertility } \\
(13 / 24)\end{array}$ & $\begin{array}{c}\text { Cancer-Related } \\
\text { Infertility (24/24) }\end{array}$ \\
\hline Label/symptom & $3(13 \%)$ & $7(29 \%)$ & $4(17 \%)$ & $9(38 \%)$ \\
Timeline & $1(4 \%)$ & $6(25 \%)$ & $5(21 \%)$ & $21(88 \%)$ \\
Cause & $2(8 \%)$ & $11(46 \%)$ & $2(8 \%)$ & $14(58 \%)$ \\
Consequence & $15(63 \%)$ & $3(13 \%)$ & $5(21 \%)$ & $19(79 \%)$ \\
Cure/control & $5(21 \%)$ & $1(4 \%)$ & $7(29 \%)$ & $17(71 \%)$ \\
\hline
\end{tabular}


Table 6 Treatments described across resources for cancer and fertility problems $(n=24)$

\begin{tabular}{|c|c|c|c|}
\hline Cancer Treatment & & Fertility Preservation Options & \\
\hline Chemotherapy & $23(96 \%)$ & Egg freezing & $22(92 \%)$ \\
\hline Radiotherapy & $23(96 \%)$ & Embryo freezing & $23(96 \%)$ \\
\hline Surgery & $17(71 \%)$ & Ovarian tissue freezing & $21(88 \%)$ \\
\hline Hormone therapy & $8(33 \%)$ & Ovarian suppression & $13(54 \%)$ \\
\hline Targeted therapy & $4(17 \%)$ & & \\
\hline Ovarian suppression as part of cancer treatment & $5(21 \%)$ & & \\
\hline Family Planning During Cancer & & $\begin{array}{l}\text { Infertility Treatment/ Family } \\
\text { Planning After Cancer }\end{array}$ & \\
\hline \multirow[t]{5}{*}{ Contraception } & $11(46 \%)$ & Natural & $17(71 \%)$ \\
\hline & & Assisted conception & $17(71 \%)$ \\
\hline & & Surrogacy & $16(67 \%)$ \\
\hline & & Adoption / fostering & $15(63 \%)$ \\
\hline & & Contraception & $12(50 \%)$ \\
\hline
\end{tabular}

Using the environmental scan method provided a rigorous way to identify fertility preservation resources $[42,74]$. Our data extraction sheet enabled us to critique resources systematically against established quality standards for written information [2, 4, 8, 69, 70]. However, there are limitations to using these type of web-based methods that may impact on our findings. Retrieving all resources is difficult due to the volume of material available on the internet $[42,46]$ and the lack of archiving and differing terminology used by developers [42]. Website content and location can change over time [75] and Google search algorithms and personalisation features

Table 7 Resource assessed for components boosting or biasing informed and shared decision making (I/SDM) ( $n=24)$ [52-54]

\begin{tabular}{|c|c|c|c|c|c|c|c|c|c|c|c|c|c|c|c|c|c|c|c|c|c|c|c|c|c|}
\hline \multirow[t]{2}{*}{ I/SDM Component } & \multicolumn{24}{|c|}{ Study Number of Resources including Component } & \multirow{2}{*}{$\begin{array}{l}\text { Number of resources } \\
\text { including component }\end{array}$} \\
\hline & 1 & 2 & 3 & 4 & 5 & 6 & 7 & 8 & 9 & 10 & 11 & 12 & 13 & 14 & 15 & 16 & 17 & 18 & 19 & 20 & 21 & 22 & 23 & 24 & \\
\hline $\begin{array}{l}\text { 1. Provides accurate information } \\
\text { about all options (IDM) }\end{array}$ & $x$ & $x$ & & $x$ & $x$ & $x$ & $x$ & & $x$ & $x$ & & $x$ & & & $x$ & $x$ & $x$ & $x$ & $x$ & $x$ & $x$ & $x$ & $x$ & $x$ & 19 \\
\hline $\begin{array}{l}\text { 2. Helps people think about what } \\
\text { matters to them about the options } \\
\text { (IDM) }\end{array}$ & & $x$ & & $x$ & & $x$ & $x$ & & & $x$ & & $x$ & & $x$ & & & & & & & & $x$ & $x$ & $x$ & 10 \\
\hline $\begin{array}{l}\text { 3. Supports reasoning about all } \\
\text { options without bias (IDM) }\end{array}$ & & & $x$ & & & & & & & & & & & & & & $x$ & & & & & $x$ & $x$ & $x$ & 5 \\
\hline $\begin{array}{l}\text { 4. Presents figures in ways to } \\
\text { support understanding (IDM) }\end{array}$ & & & & & & & & & & & & & & & & & & & & & & $x$ & & $x$ & 2 \\
\hline $\begin{array}{l}\text { 5. Encourages people to trade-off } \\
\text { their evaluations to make a choice } \\
\text { (IDM) }\end{array}$ & & & & & & & & & & & & & & & & & & & & & & $x$ & & $x$ & 2 \\
\hline $\begin{array}{l}\text { 6. Encourages people to share } \\
\text { reasoning with their health } \\
\text { professionals (SDM) }\end{array}$ & & & $x$ & $x$ & $x$ & $x$ & $x$ & $x$ & & & $x$ & $x$ & $x$ & $x$ & & $x$ & $x$ & $x$ & $x$ & $x$ & $x$ & $x$ & $x$ & $x$ & 19 \\
\hline $\begin{array}{l}\text { 7. Focuses thinking about the } \\
\text { decision in the context of their } \\
\text { lifestyle (IDM) }\end{array}$ & & & & & & & $x$ & & & & & & & & & & & & & & & & & & 1 \\
\hline $\begin{array}{l}\text { 8. Places the decision in the } \\
\text { context of a changing illness- } \\
\text { health state (IDM) }\end{array}$ & $x$ & & $x$ & $x$ & $x$ & $x$ & $x$ & $x$ & $x$ & $x$ & $x$ & $x$ & $x$ & $x$ & $x$ & $x$ & & $x$ & $x$ & $x$ & $x$ & $x$ & & $x$ & 21 \\
\hline $\begin{array}{l}9 \text { Enables decision to be } \\
\text { implemented within care pathway } \\
\text { (SDM) }\end{array}$ & & & & & & & & & & & & & & & & & & & & & & & $x$ & & 1 \\
\hline $\begin{array}{l}\text { 10. Encourages comparisons } \\
\text { between different decisions (IDM) }\end{array}$ & & & & & & & & & $x$ & & & & & & & & & & & & & $x$ & $x$ & $x$ & 4 \\
\hline Total Judgement score (out of 10) & 2 & 2 & 3 & 4 & 3 & 4 & 5 & 2 & 3 & 3 & 2 & 5 & 2 & 3 & 2 & 3 & 3 & 3 & 3 & 3 & 3 & 7 & 5 & 8 & \\
\hline
\end{tabular}


linked to geographical location and previous search history all influence the results retrieved [42, 46, 75]. Ideally more than one search engine should be searched as they use different algorithms affecting relevance rankings and subsequent resource retrieval [76], patients also use different browsers or search engines. Best practice guidance for internet searches is developing [41], conducting an environmental scan using three complementary search strategies and repeating the Google search a year later from a different organisation should help to minimise the risk of missing key resources and address some of the bias in our search methods $[42,44,74]$.

From our synthesis and critical evaluation of resources, we identified components likely to support proactively women's health literacy and reasoning in decisions which cross medical specialty. First, explicit labelling linking the current illness with the future health problem (e.g. cancer-related fertility problem) helps establish causality between the current treatment and its iatrogenic consequence. Second, including details describing the future health across all illness representation dimensions (label/ symptoms, cause, time-line, consequences, cure/control) to enable women to have a coherent understanding of the short and long-term cancer-related fertility problems arising. Third, describing the fertility preservation decisions, and presenting all options with equivalent and balanced information, to enable stakeholders to focus on details relevant for women having cancer treatment. Fourth, signposting to other fertility-related choices within the cancer treatment trajectory raises awareness for women's involvement at the right time in the cancer pathway [48] (Fig. 2). Fifth, describe risk figures and elicit preferences about the fertility preservation options to focus the discussion on information relevant to the context of starting, and minimising the consequences of, cancer treatment. Several resources encouraged women to rate their preferences for in-vitro fertilisation, surrogacy, adoption and fostering, i.e. options for women receiving treatment for fertility problems. People's' preferences are labile [77],

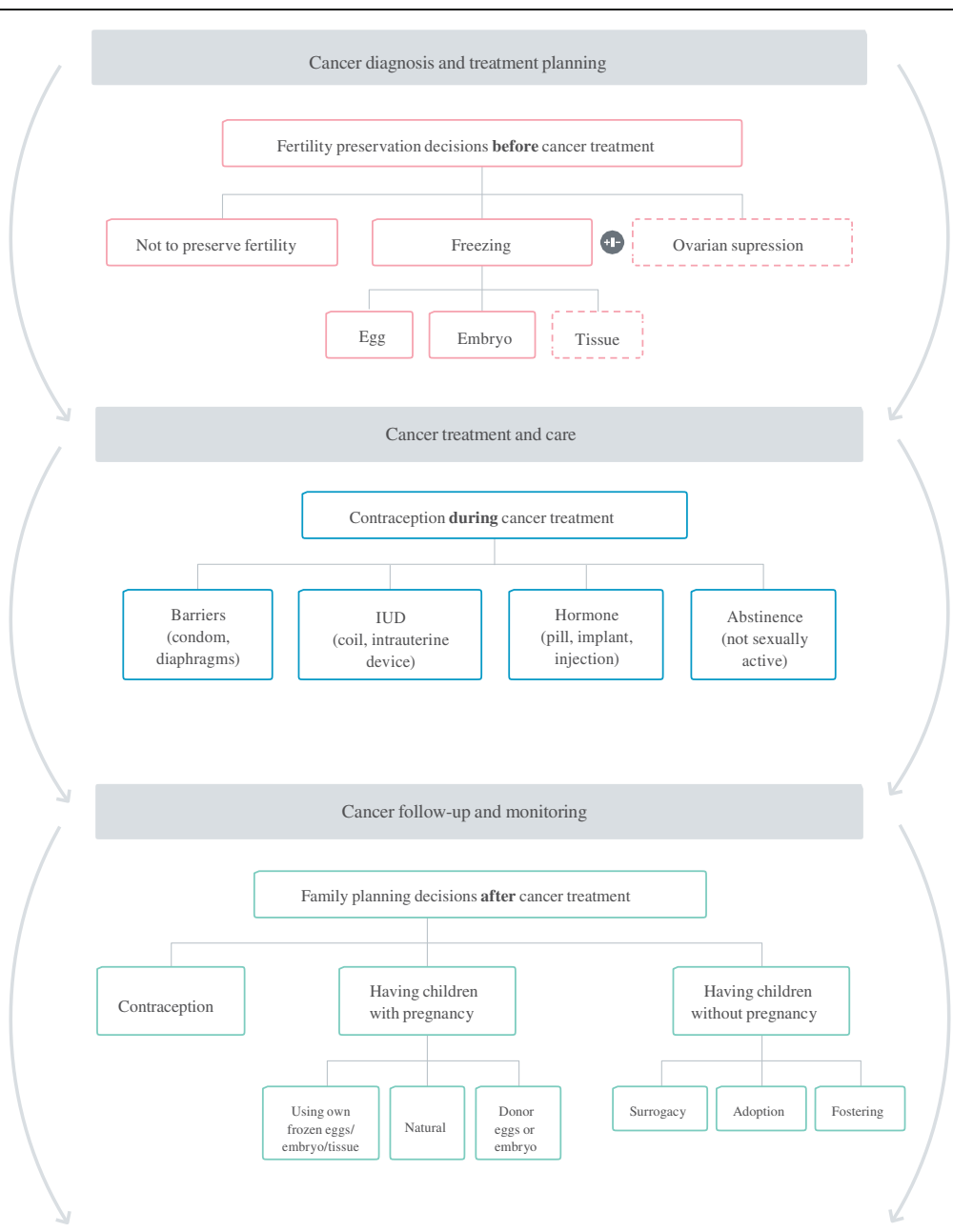

Fig. 2 Decision map integrating fertility options within cancer-care pathway [48] 
and eliciting women's values towards children, life-partners, and infertility treatments before they have a fertility problem, and whilst they are ill with cancer, may have limited value to making a decision about fertility preservation when being treated for cancer.

\section{Conclusions}

Achieving patient-centred integrated cancer care requires effective communication between patients and professionals $[23,68,78]$. Current clinical guidelines, patient resources, and patient decision aid frameworks provide little guidance enabling services to provide standardised information supporting cross-specialty decisions about health options. In consequence, there is variation in what information women receive within cancer services about fertility preservation, and can access from web-sites. We suggest components based on our study's synthesis and critical evaluation can be used in resource development guidance to inform the content and structure of patient resources, clinical guidelines and shared decision making training to support more effectively women making fertility preservation decisions before starting their cancer treatment. Providing an infrastructure to ensure adoption and maintenance of rigorously developed and evaluated patient decision aids in relevant repositories is likely to increase women' access to appropriate resources [79]. As is raising awareness and skills of utilising social science evidence when developing and designing patient information and professional guidelines to support people making healthcare decisions.

\section{Additional file}

Additional file 1: Environmental scan - open access patient decision aids cancer treatment_fertility preservation -- Data extraction form. (DOCX $31 \mathrm{~kb})$

\begin{abstract}
Abbreviations
AHRQ-NGC: Agency for Healthcare Research and Quality National Guidelines Clearinghouse; CFM-PtDA: Cancer Fertility and Me Patient Decision Aid; DALI: Decision Aids Library Inventory; HRA: Health Research Authority; IDM: Informed Decision-Making; IPDAS: International Patient Decision Aid Standards; NHS: National Health Service; NICE: National Institute of Health and Care Excellence; SN: Study Number of Resource; URL: Uniform Resource Location
\end{abstract}

\section{Acknowledgements}

We would like to thank and acknowledge the following members of the Cancer, Fertility and Me research team for all the time, expertise and comments they gave in the drafting of this manuscript for publication, and for which we are extremely grateful.

The Cancer, Fertility and Me research team include:

Galina Velikova, Leeds Teaching Hospital NHS Trust; Diana Greenfield, Sheffield Teaching Hospitals NHS Foundation Trust; Robert Phillips, Leeds Teaching Hospital NHS Trust; Sheila Lane, Oxford University Hospitals NHS Foundation Trust; Greta Brauten-Smith, Breast Cancer Care; Jacqui Gath, Independent Cancer Patients' Voices; John Snowden, Sheffield Teaching Hospitals NHS Foundation Trust; Daniel Yeomanson, Sheffield's Children NHS Foundation Trust; Ellissa Baskind, Leeds Teaching Hospital NHS Trust; Tonia Campbell, Patient Advocacy; Frances Darby, Leeds Beckett University;
Katharina Vogt, Leeds Beckett University; Jonathan Skull, Sheffield Teaching Hospitals NHS Foundation Trust; Daniel Stark, Leeds Teaching Hospital NHS Trust.

\section{Funding}

Study funded by Yorkshire Cancer Research (project award S391; 2015-2018). The funding agreement ensured the authors' independence in designing this study, interpreting the data, writing, and publishing the report. The views presented in this report are not necessarily representative of the funder's views and belong solely to the authors.

\section{Availability of data and materials}

The datasets used and/or analysed during the current study are available from the corresponding author on reasonable request.

\section{Authors' contributions}

Study idea: GLJ, HLB. All authors (GLJ, HLB, JH, NVK NM) made substantial contributions to the study design, data acquisition and interpretation. All authors (GLJ, HLB, JH, NVK NM) have been involved in drafting the manuscript critically for important intellectual content. Post-review manuscript revisions: HLB, NK, NM. All authors (GLJ, HLB, JH, NVK NM) have given final approval of the version to be published and agreed to be accountable for all aspects of the work.

\section{Ethics approval and consent to participate}

Ethics approval granted by National Health Service (NHS) Health Research Authority (HRA), East Midlands Nottingham 1 Research Ethics Committee for the project in 2016, Reference: 16/EM/0122; HRA Reference: 194751. Ethics statements are not required for the environmental scan as data extracted from publicly available written documents.

\section{Consent for publication}

Not applicable.

\section{Competing interests}

The authors declare that they have no competing interests.

\section{Publisher's Note}

Springer Nature remains neutral with regard to jurisdictional claims in published maps and institutional affiliations.

\section{Author details}

${ }^{1}$ Department of Psychology, School of Social Sciences, Leeds Beckett University, Leeds LS1 3HE, UK. ${ }^{2}$ Institute of Health Sciences - School of Medicine, University of Leeds, Leeds, UK. ${ }^{3}$ School of Health \& Related Research, University of Sheffield, Sheffield, UK.

Received: 1 June 2018 Accepted: 26 October 2018

Published online: 19 November 2018

References

1. World Health Organization. The mandate for health literacy 2016. Available from: http://www.who.int/healthpromotion/conferences/9gchp/healthliteracy/en. Accessed 17 May 2018.

2. Coulter A, Entwistle V, Gilbert D. Informing patients : an assessment of the quality of patient information materials. London: King's Fund; 1998.

3. Scott B. Readability formulas 2018. Available from: http://www. readabilityformulas.com. Accessed 17 May 2018.

4. Ley P. Communicating with patients: improving communication, satisfaction and compliance. New York: Croom Helm; 1988.

5. Nutbeam D. Health literacy as a public health goal: a challenge for contemporary health education and communication strategies into the $21 \mathrm{st}$ century. Health Promot Int. 2000;15(3):259-67.

6. Medicines and Healthcare products Regulatory Agency. Best Practice Guidance on Patient Information Leaflets 2014. Available from: https://www. gov.uk/government/uploads/system/uploads/attachment_data/file/328405/ Best_practice_guidance_on_patient_information_leaflets.pdf. Accessed 17 May 2018.

7. Sepucha KR, Abhyankar P, Hoffman AS, Bekker HL, LeBlanc A, Levin $C A$, et al. Standards for UNiversal reporting of patient decision aid 
evaluation studies: the development of SUNDAE checklist. BMJ Qual Saf. 2018;27(5):380-8.

8. The International Patient Decision Aid Standards (IPDAS) Collaboration. Criteria for Judging the Quality of Patient Decision Aids Checklist 2005. Available from: http://ipdas.ohri.ca/ipdas_checklist.pdf. Accessed 27 Mar 2018.

9. Stacey $\mathrm{D}$, Legare F, Lewis K, Barry MJ, Bennett $\mathrm{CL}$, Eden KB, et al. Decision aids for people facing health treatment or screening decisions. Cochrane Database Syst Rev. 2017;4:CD001431.

10. Winterbottom AE, Gavaruzzi T, Mooney A, Wilkie M, Davies SJ, Crane D, et al. Patient acceptability of the Yorkshire Dialysis Decision Aid (YoDDA) booklet: a prospective non-randomized comparison study across 6 Predialysis services. Perit Dial Int. 2016;36(4):374-81.

11. Meirow D, Biederman $H$, Anderson RA, Wallace WH. Toxicity of chemotherapy and radiation on female reproduction. Clin Obstet Gynecol. 2010;53(4):727-39.

12. Mauz-Korholz C, Hasenclever D, Holzendorf V, Bernstadt M, Jurgens $H$, Burdach S, et al. Feasibility of VECOPA, a dose-intensive chemotherapy regimen for children and adolescents with intermediate and advanced stage Hodgkin lymphoma: results of the GPOH-HD-2002NECOPA pilot trial. Leuk Lymphoma. 2015;56(5):1308-14.

13. Arian SE, Goodman L, Flyckt RL, Falcone T. Ovarian transposition: a surgical option for fertility preservation. Fertil Steril. 2017;107(4):e15.

14. Sato $\mathrm{S}$, Itamochi $\mathrm{H}$, Sugiyama T. Fertility-sparing surgery for uterine cervical cancer. Future Oncol. 2016;12(20):2345-55.

15. National Institute for Health and Care Excellence. Fertility problems: assessment and treatment: Clinical guideline [CG156]: NICE; 2013. Available from: https://www.nice.org.uk/guidance/cg156. Accessed 27 Mar 2018.

16. Peccatori FA, Azim HA Jr, Orecchia R, Hoekstra HJ, Pavlidis N, Kesic V, et al. Cancer, pregnancy and fertility: ESMO Clinical Practice Guidelines for diagnosis, treatment and follow-up. Ann Oncol. 2013;24 Suppl 6:vi160-70,

17. Waimey KE, Smith BM, Confino R, Jeruss JS, Pavone ME. Understanding fertility in young female Cancer patients. J Women's Health (Larchmt). 2015; 24(10):812-8.

18. Jones G, Hughes J, Mahmoodi N, Smith E, Skull J, Ledger W. What factors hinder the decision-making process for women with cancer and contemplating fertility preservation treatment? Hum Reprod Update. 2017; 23(4):433-57.

19. Lee R, Armstrong A. Chapter 17: Fertility issues in cancer treatment. In: Velikova A, Followfield L, Younger J, Board RE, Selby P, editors. Problem solving in patient-centred and integrated cancer care. Oxfordshire: EBN Health; 2018. p. 87-91.

20. Lee $S J$, Schover $L R$, Partridge $A H$, Patrizio $P$, Wallace $W H$, Hagerty $K$, et al. American Society of Clinical Oncology recommendations on fertility preservation in cancer patients. J Clin Oncol. 2006;24(18):2917-31.

21. Loren AW, Mangu PB, Beck LN, Brennan L, Magdalinski AJ, Partridge AH, et al. Fertility preservation for patients with cancer: American Society of Clinical Oncology clinical practice guideline update. J Clin Oncol. 2013;31(19):2500-10.

22. Peate M, Meiser B, Cheah BC, Saunders C, Butow P, Thewes B, et al. Making hard choices easier: a prospective, multicentre study to assess the efficacy of a fertility-related decision aid in young women with early-stage breast cancer. Br J Cancer. 2012;106(6):1053-61.

23. Woodard TL, Hoffman AS, Covarrubias LA, Holman D, Schover L, Bradford A, et al. The pathways fertility preservation decision aid website for women with cancer: development and field testing. J Cancer Surviv. 2018;12(1):101-14.

24. Woodruff TK. The Oncofertility consortium--addressing fertility in young people with cancer. Nat Rev Clin Oncol. 2010;7(8):466-75.

25. Quinn GP, Vadaparampil ST, Malo T, Reinecke J, Bower B, Albrecht T, et al. Oncologists' use of patient educational materials about cancer and fertility preservation. Psychooncology. 2012;21(11):1244-9.

26. Ehrbar V, Urech C, Rochlitz C, Dallenbach RZ, Moffat R, Stiller R, et al. Fertility preservation in young female Cancer patients: development and pilot testing of an online decision aid. J Adolesc Young Adult Oncol. 2018;7(1):30-6.

27. Garvelink MM, ter Kuile MM, Fischer MJ, Louwe LA, Hilders CG, Kroep JR, et al. Development of a decision aid about fertility preservation for women with breast cancer in the Netherlands. J Psychosom Obstet Gynaecol. 2013; 34(4):170-8.

28. Peate $\mathrm{M}$, Meiser B, Friedlander $\mathrm{M}$, Zorbas $\mathrm{H}$, Rovelli S, Sansom-Daly U, et al. It's now or never: fertility-related knowledge, decision-making preferences, and treatment intentions in young women with breast cancer--an Australian fertility decision aid collaborative group study. J Clin Oncol. 2011; 29(13):1670-7.
29. Peate M, Smith SK, Pye V, Hucker A, Stern C, Stafford L, et al. Assessing the usefulness and acceptability of a low health literacy online decision aid about reproductive choices for younger women with breast cancer: the aLLIAnCE pilot study protocol. Pilot Feasibility Stud. 2017;3:31.

30. Corney RH, Swinglehurst AJ. Young childless women with breast cancer in the UK: a qualitative study of their fertility-related experiences, options, and the information given by health professionals. Psychooncology. 2014;23(1):20-6.

31. Snyder KA, Tate A. Chapter 4: Cancer-related infertility and young women: strategies for discussing fertility preservation. In: Woodruff TK Clayman ML, Waimey KE, editors. Oncofertility communication-sharing information and building relationships across disciplines. New York: Springer; 2014. p. 49-60.

32. Garvelink MM, ter Kuile MM, Bakker RM, Geense WJ, Jenninga E, Louwe LA, et al. Women's experiences with information provision and deciding about fertility preservation in the Netherlands: 'satisfaction in general, but unmet needs'. Health Expect. 2015;18(5):956-68.

33. Peate M, Meiser B, Hickey M, Friedlander M. The fertility-related concerns, needs and preferences of younger women with breast cancer: a systematic review. Breast Cancer Res Treat. 2009;116(2):215-23.

34. Couper MP, Singer E, Levin CA, Fowler FJ Jr, Fagerlin A, Zikmund-Fisher BJ. Use of the internet and ratings of information sources for medical decisions: results from the DECISIONS survey. Med Decis Mak. 2010;30(5 Suppl):106S-14S.

35. Hoffman AS, Volk RJ, Saarimaki A, Stirling C, Li LC, Harter M, et al. Delivering patient decision aids on the Internet: definitions, theories, current evidence, and emerging research areas. BMC Med Inform Decis Mak. 2013;13 Suppl 2:S13.

36. Medlock S, Eslami S, Askari M, Arts DL, Sent D, de Rooij SE, et al. Health information-seeking behavior of seniors who use the internet: a survey. J Med Internet Res. 2015;17(1):e10.

37. Morris D, Drake E, Saarimaki A, Bennett C, O'Connor A. Can people find patient decision aids on the internet? Patient Educ Couns. 2008;73(3):557-60.

38. Sbaffi L, Rowley J. Trust and credibility in web-based health information: a review and agenda for future research. J Med Internet Res. 2017;19(6):e218.

39. Legare $F$, Thompson-Leduc P. Twelve myths about shared decision making. Patient Educ Couns. 2014;96(3):281-6.

40. Pollard S, Bansback N, Bryan S. Physician attitudes toward shared decision making: a systematic review. Patient Educ Couns. 2015;98(9):1046-57.

41. Cooper C, Booth A, Britten N, Garside R. A comparison of results of empirical studies of supplementary search techniques and recommendations in review methodology handbooks: a methodological review. Syst Rev. 2017;6(1):234.

42. Godin K, Stapleton J, Kirkpatrick SI, Hanning RM, Leatherdale ST. Applying systematic review search methods to the grey literature: a case study examining guidelines for school-based breakfast programs in Canada. Syst Rev. 2015;4(1):138

43. Graham P, Evitts T, Thomas-MacLean R. Environmental scans: how useful are they for primary care research? Can Fam Physician. 2008;54(7):1022-3.

44. Leiva Portocarrero ME, Garvelink MM, Becerra Perez MM, Giguere A, Robitaille $\mathrm{H}$, Wilson BJ, et al. Decision aids that support decisions about prenatal testing for Down syndrome: an environmental scan. BMC Med Inform Decis Mak. 2015;15:76.

45. Centre for Reviews Dissemination. Systematic Reviews: CRD's Guidance for Undertaking Reviews in Healthcare. York: Centre for Reviews \& Dissemination; 2009. Available from: https://www.york.ac.uk/media/crd/ Systematic_Reviews.pdf. Accessed 2 Sept 2018.

46. Mahood Q, Van Eerd D, Irvin E. Searching for grey literature for systematic reviews: challenges and benefits. Res Synth Methods. 2014;5(3):221-34.

47. Moher D, Liberati A, Tetzlaff J, Altman DG. Preferred reporting items for systematic reviews and meta-analyses: the PRISMA statement. PLoS Med. 2009;6(7):e1000097.

48. Jones GL, Bekker H, Velikova G, Collins K, Skull J, et al. The Cancer, Fertility and Me Patient Decision Aid: Yorkshire Cancer Research (S391); 2017.

49. Jones GL, Bekker H, Velikova G, Collins K, Skull J, et al. Cancer, Fertility and Me: The development and evaluation of a fertility preservation decision support intervention to support women with cancer in Yorkshire: Yorkshire Cancer Research (S391), 1st July 2015; 2015.

50. Jones GL, Hughes J, Mahmoodi N, Greenfield D, Brauten-Smith G, Skull J, et al. Observational study of the development and evaluation of a fertility preservation patient decision aid for teenage and adult women diagnosed with cancer: the Cancer, fertility and me research protocol. BMJ Open. 2017;7(3):e013219.

51. Coulter A, Stilwell D, Kryworuchko J, Mullen PD, Ng CJ, van der Weijden T. A systematic development process for patient decision aids. BMC Med Inform Decis Mak. 2013;13 Suppl 2:S2. 
52. Bekker H, Thornton JG, Airey CM, Connelly JB, Hewison J, Robinson MB, et al. Informed decision making: an annotated bibliography and systematic review. Health Technol Assess. 1999;3(1):1-156.

53. Bekker HL, Hewison J, Thornton JG. Understanding why decision aids work: linking process with outcome. Patient Educ Couns. 2003;50(3):323-9.

54. Winterbottom A, Conner M, Mooney A, Bekker HL. Evaluating the quality of patient leaflets about renal replacement therapy across UK renal units. Nephrol Dial Transplant. 2007;22(8):2291-6.

55. Horne R, Weinman J. Patients' beliefs about prescribed medicines and their role in adherence to treatment in chronic physical illness. J Psychosom Res. 1999;47(6):555-67.

56. Leventhal H, Brissette I, Leventhal EA, editors. Chapter 3: the common-sense model of self-regulation of health and illness. New York: Routledge, Taylor \& Francis Group; 2003

57. Abhyankar P, Volk RJ, Blumenthal-Barby J, Bravo P, Buchholz A, Ozanne E, et al. Balancing the presentation of information and options in patient decision aids: an updated review. BMC Med Inform Decis Mak. 2013;13 Suppl 2:S6.

58. Bekker HL, Winterbottom AE, Butow P, Dillard AJ, Feldman-Stewart D, Fowler FJ, et al. Do personal stories make patient decision aids more effective? A critical review of theory and evidence. BMC Med Inform Decis Mak. 2013;13 Suppl 2:S9.

59. Feldman-Stewart D, O'Brien MA, Clayman ML, Davison BJ, Jimbo M Labrecque $M$, et al. Providing information about options in patient decision aids. BMC Med Inform Decis Mak. 2013;13 Suppl 2:S4

60. Garvelink MM, ter Kuile MM, Stiggelbout AM, de Vries M. Values clarification in a decision aid about fertility preservation: does it add to information provision? BMC Med Inform Decis Mak. 2014;14:68.

61. Trevena LJ, Zikmund-Fisher BJ, Edwards A, Gaissmaier W, Galesic M, Han PK, et al. Presenting quantitative information about decision outcomes: a risk communication primer for patient decision aid developers. BMC Med Inform Decis Mak. 2013;13 Suppl 2:S7.

62. Bekker HL, Hewison J, Thornton JG. Applying decision analysis to facilitate informed decision making about prenatal diagnosis for Down syndrome: a randomised controlled trial. Prenat Diagn. 2004;24(4):265-75.

63. Abhyankar P, Bekker HL, Summers BA, Velikova G. Why values elicitation techniques enable people to make informed decisions about cancer trial participation. Health Expect. 2011;14(Suppl 1):20-32.

64. Fagerlin A, Pignone M, Abhyankar P, Col N, Feldman-Stewart D, Gavaruzzi T, et al. Clarifying values: an updated review. BMC Med Inform Decis Mak. 2013;13 Suppl 2:S8.

65. Pieterse $A H$, de Vries M, Kunneman M, Stiggelbout AM, Feldman-Stewart D. Theory-informed design of values clarification methods: a cognitive psychological perspective on patient health-related decision making. Soc Sci Med. 2013;77:156-63.

66. Witteman HO, Gavaruzzi T, Scherer LD, Pieterse AH, Fuhrel-Forbis A, Chipenda Dansokho $S$, et al. Effects of design features of explicit values clarification methods: a systematic review. Med Decis Mak. 2016;36(6):760-76.

67. McCaffery KJ, Holmes-Rovner M, Smith SK, Rovner D, Nutbeam D, Clayman $M L$, et al. Addressing health literacy in patient decision aids. BMC Med Inform Decis Mak. 2013;13 Suppl 2:S10.

68. Légaré F, Stacey D. Chapter 11: an interprofessional approach to shared decision making: what it means and where next. In: Woodruff TK, Clayman ML, Waimey KE, editors. Oncofertility communication-sharing information and building relationships across disciplines. New York: Springer; 2014. p. 131-9.

69. Elwyn G, O'Connor A, Stacey D, Volk R, Edwards A, Coulter A, et al. Developing a quality criteria framework for patient decision aids: online international Delphi consensus process. BMJ. 2006;333(7565):417.

70. Joseph-Williams N, Newcombe R, Politi M, Durand MA, Sivell S, Stacey D, et al. Toward minimum standards for certifying patient decision aids: a modified Delphi consensus process. Med Decis Mak. 2014;34(6):699-710.

71. LaBrecque SF, Wallach H, Waimey KE. Oncofertility communication tools for professionals and the public. In: Woodruff TK, Clayman ML, Waimey KE, editors. Oncofertility communication-sharing information and building relationships across disciplines. New York: Springer; 2014. p. 141-53.

72. Quinn GP, Vadaparampil ST, Sehovic I, Clayman ML. Chapter 3: patient and family tools to aid in education and decision-making about oncofertility. In: Woodruff TK, Clayman ML, Waimey KE, editors. Oncofertility communication-sharing information and building relationships across disciplines. New York: Springer; 2014. p. 35-48.
73. Herrmann A, Mansfield E, Hall AE, Sanson-Fisher R, Zdenkowski N. Wilfully out of sight? A literature review on the effectiveness of cancer-related decision aids and implementation strategies. BMC Med Inform Decis Mak. 2016:16:36

74. Stansfield C, Dickson K, Bangpan M. Exploring issues in the conduct of website searching and other online sources for systematic reviews: how can we be systematic? Syst Rev. 2016;5(1):191.

75. Briscoe S. Web searching for systematic reviews: a case study of reporting standards in the UK health technology assessment programme. BMC Res Notes. 2015;8:153

76. Collaboration for Environmental Evidence. Guidelines and Standards for Evidence Synthesis in Environmental Management. Version 5.0. 2018 [Accessed 2 Sept 2018]. Available from: http://www.environmentalevidence. org/guidelines/table-of-contents.

77. Stiggelbout AM. Chapter 11: assessing Patients' preferences. In: Chapman GB, Sonnenberg FA, editors. Decision making in health care: theory, psychology, and applications. Cambridge: Cambridge University Press; 2000. p. 289-312.

78. Selby P, Board RE, Velikova G. Chapter 1: Patient-centred and integrated cancer care. In: Velikova A, Followfield L, Younger J, Board RE, Selby P, editors. Problem solving in patient-centred and integrated cancer care. Oxfordshire: EBN Health; 2018. p. 1-5.

79. Coulter A, Härter MH, Moumjid-Ferdjaoui N, Perestelo-Perez L, van der Weijden T. European experience with shared decision making. Int J Person Cent Med. 2015;5(1):9-14.
Ready to submit your research? Choose BMC and benefit from:

- fast, convenient online submission

- thorough peer review by experienced researchers in your field

- rapid publication on acceptance

- support for research data, including large and complex data types

- gold Open Access which fosters wider collaboration and increased citations

- maximum visibility for your research: over $100 \mathrm{M}$ website views per year

At $\mathrm{BMC}$, research is always in progress.

Learn more biomedcentral.com/submissions 